\title{
Sulfur isotopic composition of the Tristan-Gough plume source
}

\author{
CORNELIA CLASS ${ }^{1}$, EMILIE THOMASSOT ${ }^{2}$, ANTON LE \\ ROEX $^{3}$ AND CATHERINE CHAUVEL ${ }^{4}$ \\ ${ }^{1}$ Lamont-Doherty Earth Observatory of Columbia University \\ ${ }^{2}$ Université de Lorraine, CNRS, CRPG \\ ${ }^{3}$ University of Cape Town \\ ${ }^{4}$ Université de Paris, Institut de Physique du Globe de Paris, \\ CNRS UMR 7154
}

Presenting Author: class@1deo.columbia.edu

Sulfur isotopes offer new insights into the origin of Earth's mantle heterogeneity. At present-day, processes modifying sulfur produce isotopic fractionations that depend on the relative mass differences between its different isotopes. In contrast, Archean/earliest Proterozoic sediments exhibit massindependently fractionated sulfur isotopes (MIF-S) acquired through photochemical reactions in the oxygen-poor atmosphere. The persistence of recycled MIF-S through subduction and eventual rise in a mantle plume has been demonstrated in two studies of single sulfide inclusions in phenocrysts for two South Pacific plumes [1,2] of HIMU and EMI endmember composition. The time constraints placed on the recycled component of the HIMU and EMI endmembers by S-MIF raises the question whether this might represent a general feature of plumes with such geochemical affinities.

Here we present sulfur isotopes of 46 mineral-hosted sulfide inclusions from 11 rocks from Tristan (Tristan da Cunha, Inaccessible, Nightingale) and Gough islands, the most recent activity of the major 130 Ma-long-lived EMI-type Tristan-Gough plume system with a root at the core-mantle boundary related to the African LLSVP. Data sets from Tristan and Gough are distinct, consistent with the lateral $\mathrm{Pb}-\mathrm{Nd}-\mathrm{Hf}$ isotopic zonation of this plume [3]. Gough is characterized by $\delta^{34} \mathrm{~S}$ close to zero, and a range in $\Delta^{33} \mathrm{~S}$ from zero to slightly positive values with the most extreme inclusion exhibiting positive MIF-S averaging at $\Delta^{33} \mathrm{~S}=+0.25 \pm 0.09 \%$ (stdev, $\left.\mathrm{n}=6\right)$. Tristan has negative $\delta^{34} \mathrm{~S}-7$ to $-0.9 \%$ and $\Delta^{33} \mathrm{~S}$ from -0.23 to $+0.23 \%$ with an average of $-0.04 \pm$ $0.12 \%($ stdev, $\mathrm{n}=34)$ and no clear indication for MIF-S. Although Tristan and Gough have $\mathrm{Sr}-\mathrm{Nd}-\mathrm{Hf}-\mathrm{Pb}$ isotopic characteristics with affinity to the enriched mantle I (EMI) global mantle endmember, they clearly exhibit distinct sulfur isotopic characteristics from each other and also distinct from EMI-type Pitcairn, with no MIF-S in Tristan, negative $\mathrm{D}^{33} \mathrm{~S}$ in Pitcairn and positive $\Delta^{33} \mathrm{~S}$ in Gough. Despite variable origin, MIF-S in both Pitcairn and Gough suggests their EMI-type sources contain recycled surface material that is $>2.45$ Ga old.

[1] Cabral et al. (2013), Nature 496, 490-494. [2] Delavault et al. (2016), PNAS 113, 12,952-12,956. [3] Rohde et al. (2013), Geology 41, 335-338. 